ABCD Arq Bras Cir Dig

2007;20(4):297-9

Relato de caso

\title{
CISTO GIGANTE DE COLÉDOCO
}

\author{
Giant choledochal cyst
}

\author{
Olival Cirilo Lucena da FONSECA-NETO, Hermes Willer Olinda SANT'ANA, \\ Luciana Marins CAVALCANTI, Antônio Lopes de MIRANDA
}

ABCDDV/578

Fonseca-Neto OCL, Sant'ana HWO, Cavalcanti LM, Miranda AL. Cisto gigante de colédoco. ABCD Arq Bras Cir Dig 2007;20(4):297-9

RESUMO - Introdução - A doença cística das vias biliares é anomalia congênita que pode acometer as vias biliares intra e/ou extra-hepáticas. A extra-hepática inclui os cistos de colédoco e a intra-hepática é conhecida por Doença de Caroli. Os cistos de colédoco de tamanho gigante são muito raros. Objetivo** - Relatar o caso de um cisto de colédoco de tamanho gigante em uma paciente feminina. Relato do caso - Mulher de 19 anos foi admitida com história de icterícia e acolia fecal há sete dias. Referia dor epigástrica associada com ingestão de dieta rica em gordura. Nos antecedentes pessoais relatou dois episódios de icterícia, aos 8 e 14 anos, que progrediram espontaneamente. No exame físico apresentava icterícia $(+3 /+4)$ e uma massa palpável indolor em mesogástrio foram os únicos achados. A ultrassonografia demonstrou grande formação cística de paredes finas adjacente ao hepatocolédoco, pâncreas e rim direito que media 18,5 x 10,2 cm. A colangioressonância confirmou o grande cisto de colédoco e hepatojejunoanastomose em "Y" de Roux após excisão do cisto e colecistectomia foi realizada. A formação cística media 20 x 15,5 x 12,5 cm e com um volume médio de $1000 \mathrm{~mL}$. A paciente encontra-se em acompanhamento ambulatorial sem alterações hepatobiliares após o sétimo mês da operação. Conclusão - O cisto de colédoco deve fazer parte do diagnóstico diferencial em pacientes adultos jovens com icterícia e massa palpável; no entanto, a diferenciação entre ele e neoplasia maligna deve ser pesquisada.

DESCRITORES - Cisto, colédoco. Doença de Caroli **A Roberta adicionou. PODE?

\section{INTRODUÇÃO}

A doença cística das vias biliares é anomalia congênita que pode acometer as vias biliares intra e/ou extra-hepáticas $^{2}$. A doença extra-hepática inclui os cistos de colédoco e a intra-hepática é conhecida por Doença de Caroli². Apresenta incidência muito variável, podendo ser de 1 em 13.000 a 15.000 habitantes, nos países ocidentais, e até $1 \mathrm{em}$ cada 1.000 habitantes nos países orientais. O sexo feminino é o mais acometido. Em $60 \%$ dos casos o diagnóstico é realizado na infância ${ }^{1}$. A apresentação clínica clássica é representada pela tríade: dor abodminal, icterícia e massa palpável em hipocôndrio direito.

O primeiro caso descrito de cisto congênito de colédoco foi realizado por Váter, em $1723^{1}$. Alonso-Lej ${ }^{1}$ sugeriu classificação para os cistos do colédoco (tipo I, II e III) e propôs tratamento individualizado. Em 1977, Todani ${ }^{1,2}$, reclassifica essa entidade cística em cinco tipos, além disso, realiza revisão na fisiopatologia e na conduta. A sua classificação é usada até hoje $\mathrm{e}^{1,2}$.

O objetivo do presente estudo é relatar um caso de cisto de colédoco de tamanho gigante, histopatologicamente comprovado em um adulto.

Trabalho realizado no Departamento de Clínica Cirúrgica do Hospital Geral Universitário (HGU) da Faculdade de Medicina da Universidade de Cuiabá - UNIC, Cuiabá, MT, Brasil.

Endereço para correspondência: Jair Gimenez Marra, e-mail: marrajair@uol.com.br

\section{RELATO DO CASO}

Paciente do sexo feminino, 19 anos, casada, natural e procedente de Panelas, PE. Foi admitida no Serviço de Cirurgia Geral do Hospital da Restauração, Recife, PE com história de icterícia e acolia fecal há sete dias. Referia dor epigástrica associada com ingestão de dieta rica em gordura. Nos antecedentes pessoais relatou dois episódios de icterícia, aos oito e 14 anos, que progrediram espontaneamente. No exame físico apresentava icterícia $(+3 /+4)$ e uma massa palpável indolor em mesogástrio como únicos achados. A ultrassonografia demonstrou grande formação cística de paredes finas adjacente ao hepatocolédoco, pâncreas e rim direito que media 18,5 x 10,2 $\mathrm{cm}$. A colangioressonância confirmou o grande cisto de colédoco (Figura 1) e foi realizada a ressecção sem intercorrências. O procedimento operatório foi hepatojejunoanastomose em "Y" de Roux, após excisão do cisto e colecistectomia. A formação cística media $20 \times 15,5 \times 12,5 \mathrm{~cm}$ com volume médio de $1000 \mathrm{~mL}$ (Figura 2). Apresentou no pós-operatório infecção do sítio cirúrgico superficial tratado com cuidados locais e recebeu alta hospitalar no $16^{\circ}$ dia de pós-operatório. A paciente encontra-se em acompanhamento ambulatorial sem alterações hepatobiliares após o $7^{\circ}$ mês da operação. 


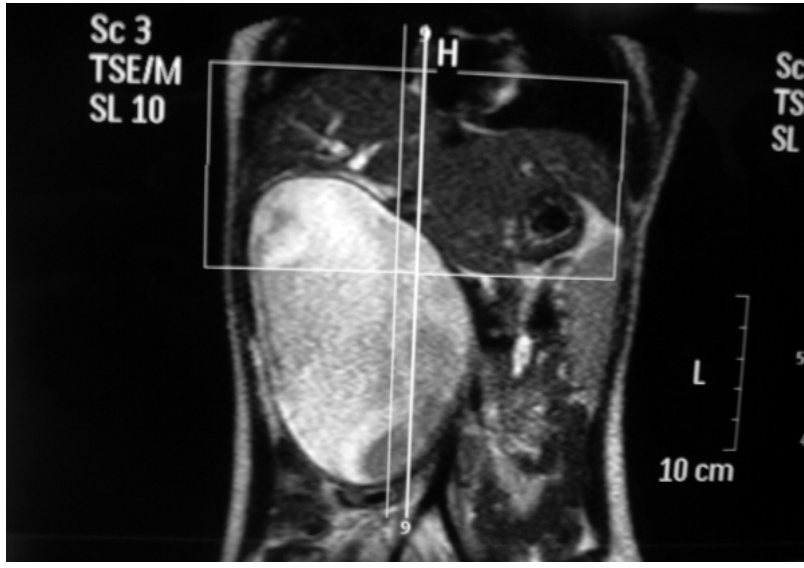

FIGURA 1 - Ressonância nuclear magnética mostrando grande cisto de colédoco.

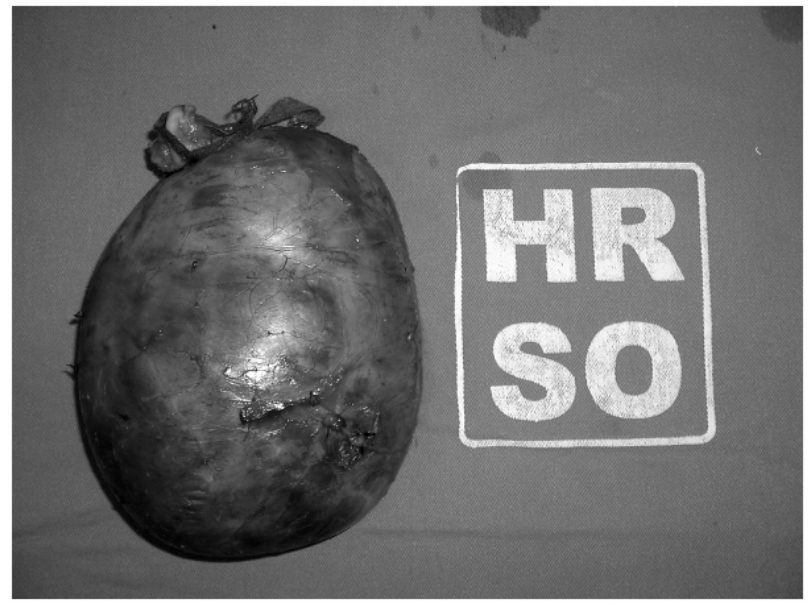

FIGURA 2 - Peça cirúrgica ressecada mostrando detalhes do cisto de colédoco

\section{DISCUSSÃO}

A doença cística das vias biliares é também conhecida como cistos do colédoco. A dilatação pode ocorrer desde os ductos biliares intra-hepáticos até a porção intraduodenal do ducto biliar ${ }^{1,2}$.

A incidência no Japão é 150 vezes maior do que no ocidente. Os cistos do colédoco são de três a oito vezes mais comuns em mulheres do que em homens. Apenas $20 \%$ são diagnosticados na vida adulta ${ }^{3}$.

A patogenia deles é multifatorial. Junção anômala do ducto biliar e ducto pancreático, disfunção do esfíncter hepatoduodenal, alteração da inervação autônoma do colédoco terminal, infecção viral provocando agangliose do colédoco distal, predisposição genética, defeito embrionário na epitelização e recanalização dos ductos biliares, são algumas das hipóteses aventadas para explicar a formação do cisto do colédoco 5 .

No entanto, mesmo com causa não definida claramente, a presença da junção anômala da via biliar/ducto pancreático vem sendo demonstrada em mais de $95 \%$ das crianças e acima de $90 \%$ dos adultos quando estes são investigados através da colangiopancreatografia endoscópica retrógrada (CPER). Dentro das complicações oriundas do cisto do colédoco, malignização é a mais temida. A sua associação é estimada em 1000 a 2000 vezes maior do que a população geral ${ }^{5}$.

A proposta inicial de classificação foi sugerida por Alonso-Lej em 1959 e, posteriormente, modificada por Todani, em $1977^{1}$. Essa última é aceita até hoje e dividese em: tipo I - cisto extra-hepático segmentar, cilíndrico ou fusiforme; tipo II - divertículo supraduodenal; tipo III - divertículo intraduodenal, coledococele; tipo IV a - cistos múltiplos intra e extra-hepáticos; tipo IV b - cistos múltiplos extra-hepáticos e tipo $\mathrm{V}$ - cistos múltiplos intrahepáticos, Doença de Caroli ${ }^{1,3,5}$.

A apresentação clínica difere entre crianças e adultos, sendo que nestes freqüentemente estão presentes dor abdominal e icterícia.

Exames complementares não invasivos, ultrassonografia, tomografia e a ressonância, devem ser utilizados para o diagnóstico ser confirmado e orientar o tratamento específico. Com o advento da CPER as anomalias da junção biliopancreática podem ser diagnosticadas.

A operação recomendada é a colecistectomia com ressecção do cisto e reconstrução biliar com alça exclusa (hepatojejunoanastomose em "Y" de Roux). A mortalidade operatória é baixa $(<2,5 \%)$ e a infecção do sítio cirúrgico é a principal complicação imediata. Fístula e estenose biliar também podem ocorrer e o seu manejo é conservador ${ }^{4}$.

\section{CONCLUSÃo}

O cisto de colédoco deve fazer parte do diagnóstico diferencial em pacientes adultos jovens com icterícia e massa palpável; no entanto, a manifestação não usual de cisto de grande tamanho deve chamar atenção para o diagnóstico diferencial com doenças neoplásicas.

Fonseca-Neto OCL, Sant'ana HWO, Cavalcanti LM, Miranda AL. Giant choledochal cyst. ABCD Arq Bras Cir Dig 2007;20(4):297-9

ABSTRACT - Background - Choledochal cyst represents a rare congenital anomaly, eventually associated with intra and extrahepatic biliary tract disorders. Extrahepatic diseases include choledochal cysts and congenital dilation of the lower intrahepatic bile duct is known as Caroli's disease. Giant choledochal cyst constitutes a very rare abnormality. Aim - To report a giant choledochal cyst in a female patient. Case Report - A 19-year-old woman was admitted presenting history of icterus and fecal acholia for 7 days. Patient referred epigastric pain related to fat ingestion. Previously she presented two episodes of icterus, 8 years and 14 years old, with spontaneously regression. Physical examination showed icterus $(+3 /+4)$ and palpable asymptomatic abdominal mass. Ultrasound investigation demonstrated a thin wall big cystic formation adjacent to hepatocholedochal, pancreas, and right kidney, $18,5 \times 10,2 \mathrm{~cm}$ in size. Magnetic resonance cholangiography confirmed the giant choledochal cyst. Hepaticojejuno anastomosis in Roux-en-Y after cystic resection and cholecistectomy were performed. Cystic formation measured $20 \mathrm{x} 15,5 \times 12,5$ $\mathrm{cm}$ and presented a volume approximately $1000 \mathrm{~mL}$. Since the seventh month after surgery procedure, no evidence of jaundice has been detected in follow-up visiting. Conclusion - Choledochal cyst must be considered as a differential diagnosis in young adults presenting with icterus and palpable mass; although, neoplasia must also be investigated.

HEADINGS - Choledochal cyst. Caroli disease. ** a Roberta adicionou 


\section{REFERÊNCIAS}

1. Akarauiputh T, Boonnuch W, Watanapa P, Lert - Akayamanee N, Lohsiriwat D. Surgical management of adult choledochal cysts. J Med Assoc Thai 2005; 88(7):939-43.

2. Nain RK, Sarita M, Simi R, Alka C, Atul S. Choledochal cyst in children: 15-year experience. Indian J Gastroenterol 2006; 24(4):178-179.

3. Safiollas MC, Moulakakis KG, Misiakos EP, Lygidakis NJ. Surgical management of choledochal cysts in adult. Hepatogastroenterology 2005; 52(64):1030-3
4. Visser BC, Suh I, Way LW, Mang SM. Congenital choledochal cysts in adults. Arch Surg 2004; 139:855-62.

5. Yu ZL, Zhang LJ, Fu JZ. Anomalous pancreaticobiliary junction: image-analysis and treatment principles. Hepatobiliary Pancreat Dis Int 2004; 3:136-9.

Conflito de interesse: não há Fonte financiadora: não há Recebido para publicação em: 05/06/2007 Aceito para publicação em: 08/10/2007 